\title{
Online Cooperative Learning and Key Interpsychological Mechanisms: An Exploratory Study through the Analysis of the Discourse Content
}

\author{
Marly Casanova ${ }^{1}$, Ibis M. Alvarez ${ }^{2}$ \\ ${ }^{1}$ Unit of Curriculum and Assessment, Ministry of Education of Chile, Región de los Ríos, Chile \\ ${ }^{2}$ Educational and Developmental Psychology Department, Universitat Autònoma de Barcelona, Barcelona, Spain \\ Email: ibismarlene.alvarez@uab.es
}

Received October $3^{\text {rd }}$, 2012; revised November $5^{\text {th }}$, 2012; accepted November $19^{\text {th }}, 2012$

\begin{abstract}
This research analyses the cooperative learning process in three groups applying the case study technique in a virtual university asynchronous communication context. The exploratory study was performed within a subject taught at a Master in e-learning programme. Based on a review of the theory and the current status of research, we delineate the concept of virtual cooperative learning and the main interpsychological mechanisms accounting for its effectiveness. Through a case study methodology and by means of discourse analysis, we identify the main interpsychological mechanisms involved in peer cooperation-positive interdependence, construction of meaning and psychosocial relations. We categorise the types of language involved in the process of joint construction of meaning all throughout the sequence of cooperative learning being studied.
\end{abstract}

Keywords: Cooperative Learning; Computer-Mediated Communication; Interactive Learning Environments; Discourse Analysis

\section{Introduction}

Online cooperative learning in asynchronous contexts offer diverse opportunities to promote regulated behaviours that may support joint construction of meaning (Dillenbourg, Schneider, \& Synteta, 2002). Nevertheless, teachers often comment that student conversations in cooperative learning task can be disappointing. Students, they contend, can be insufficiently focused on the content of their activity and the quality of their group product. The scarcity of the academic content in group discussions often stems from a lack of clarity on the part of students and teachers as to what should be make (Abram et al., 2002).

To arrange for a fruitful learning environment, teachers need to take advantage of the possibilities given by this learning environment and to try to reduce the problems. In this sense, the purposes of this study is to identify the main interpsychological mechanisms involved in the process of virtual cooperative asynchronous communication learning by means of content analysis of online discussion. As the result, we intend to delineate discourse categories that will allow us to examine positive interdependence among group members, the construction of meaning and the psychosocial relations among a virtual cooperative group.

\section{Theoretical Approach}

Recently, researchers have shifted their focus to being more interested in identifying the mediating factors and the interpsychological mechanisms involved in the effectiveness of cooperative learning (see for example Durán \& Monereo, 2005; Hogan, Nastasi, \& Pressley, 2000; Jonassen \& Kwon, 2001; Lipponen, Rahikainen, Hakkarainen, \& Palonen, 2002; Van Boxtel, Van der Linden, \& Kanselaar, 2000; Volet, Summers, \& Thur- man, 2008).

There is little knowledge on this specific topic when applied to virtual education; however, contrastive information from faceto-face education on the effectiveness of cooperative learning techniques and the required specific processes, can prove useful in furthering understanding of their internal dynamics in virtual contexts (Casanova, 2008; Laurillard, 2009).

Beyond the discussion about the cooperation and collaboration concepts, in the practice, both processes are referred to active and interactive learning (Panitz, 1996). In fact, cooperative learning groups rely on positive interdependence among the constituents of the group. The students feel they can reach their learning goals only if the rest of the group also achieve them (Johnson \& Johnson, 1999). But not all groupings are cooperative, since the latter form can only be accomplished by observing certain basic elements. Rusbult and Van Lange (2003) point out that it is necessary to gain further understanding of interdependence so as to appreciate how these processes are transformed in communication, how motivational factors and the concern for the welfare of another member of the group intervene during the interaction, and their effects on goal accomplishment.

The effectiveness of cooperative learning depends upon multiple conditions such as the group composition (size, age, gender, heterogeneity...), the task features and the communication media. However, these conditions are multiple and interact with each other in such a complex way that is not possible to guarantee learning effects (Dillenbourg, 2002).

According with sociocultural theories, verbal interaction is particularly essential in cognitive development and learning (Cazden, 1988; Edwards and Mercer 1987; Mercer, 2004; Wertsch, 1985). The teaching-learning process is viewed as a so- 
cially organised activity in which speech processes take place among people of different levels of command whether more or less competent. In other words and more specifically, in cooperative learning tasks, language is the basic tool to collectively understand, co-regulate, make proposals, negotiate and construct meaning.

Of great value is also the research carried out on the characteristics of virtual asynchronous communication (De Wever, Schellens, Valcke, \& Van Keer, 2006; Naidu \& Järvelä, 2006; Schrire, 2006) and its differences in relation to the communication established in other educational contexts, as well as the studies performed on virtual communities, especially those analysing the process of interaction through discourse, which contribute relevant theoretical and methodological elements that can be applied in a deeper study of the virtual cooperative learning process (e.g. Garrison \& Anderson, 2003; Gunawardena, Lowe, \& Anderson, 1997; Han \& Hill, 2007; Marcelo \& Perera, 2007).

In the virtual learning environment, the majority of educational interaction relies on the use of discourse-in many instances in a written format-as a mediating instrument to conceptualise reality, discuss and negotiate (e.g. Järvela \& Hakkinen, 2002; Wegerif, 2006). In this sense, the students' discursive activity is partly responsible for their ability to achieve higher levels of intersubjectivity and, therefore, advance towards shared and ever more complex representations of the contents and tasks of the joint activity.

From a sociocultural constructivist point of view, learning processes in an online learning environment are described as the construction of shared meanings, and the importance of discourse as a basic mediating tool for this construction is underlined (Hogan, Nastasi, \& Pressley, 2000; Hung \& Der-Thanq, 2001; Salmon, 2002). In this sense, the participants' discursive activity is set within the larger context of the activity.

Likewise, cooperative knowledge construction in virtual environments requires high levels of continuous interaction and reciprocal communication between the participants, allowing argumentation, negotiation, discussion and the joint construction of meanings (Kanuka \& Anderson, 1998). Within this kind of interaction, different interpsychological mechanisms that favour the constructive potential of the interaction between the students may occur. Therefore, a crucial element for understanding how knowledge is constructed has to do with what is being done and said by all the participants (see for example Onrubia \& Engel, 2010).

Along these lines, Mercer (2000) distinguishes the types of talk taking place in the classroom: disputative, cumulative or exploratory. Disputative or discussion talk is characterised by disagreement, making decisions individually, brief exchanges consisting of statements and discussions of doubtful points or refutations. Cumulative talk is characterised by repetitions and confirmations, speakers build on what others have said in a positive way, but not critically; they construct "shared knowledge" by means of accumulation. With exploratory talk, however, knowledge is more openly justified and reasoning is apparent in the conversation. Other students' ideas are discussed in a critical and constructive manner. Statements and suggestions are offered for joint consideration, they must be questioned and defended, but discussion on doubtful points must be justified and alternative hypotheses offered.

According to Mercer (2004), the sociocultural analysis of classroom discourse is basically geared to understanding how language is used to think collectively and it focuses on the importance of dialogue quality in educative processes. Take into in account, this point of view; we believe the following interpsychological mechanisms, related with the cooperative learning (Johnson \& Johnson, 1999) are essential in order to analysis how knowledge is constructed also in an online environment:

1) Positive interdependence among the group members in the execution of the learning activity. Most researchers, both in face-to-face and in virtual environments, focus on achieving a common goal, which involves performing a joint task or piece of work, requiring commitment and accountability from the constituents of the group (Brewer \& Klein 2006; Chou, 2003).

2) Psychosocial relations. Many authors stress the importance of interpersonal relations and the social skills of group members in ensuring cooperation and achieve positive effects in learning. They posit that the degree of emotive bonding and social support among students has an impact on the quality of their joint work (e.g. Garrison \& Anderson, 2003; Jermann \& Dillenbourg, 2008; Perit, Zemel, \& Stahl, 2009).

3) Joint construction of meaning through language. This involves the joint construction of knowledge, ideas and concepts; demanding and offering explanations and arguments; mutually negotiating and regulating the contributions and viewpoints in the interaction. The students' different uses of language are given in sequence, which produce expositive, descriptive and argumentative texts, as well as conclusions and summaries (e.g. Alvarez \& López, 2010; Ludvigsen, 2011; Schrire, 2006).

Additionally, we take into account that written language is the base of the communication and interaction in Computer Supported Collaborative Learning (CSCL) situations where communication is asynchronous (Garrison, Anderson, \& Archer, 2000). Much of cited researches have focused on content analysis of the transcriptions of the online conversation in order to investigate the quality of the interaction process in which the students engage.

Finally, as a result of the consideration of the discourse as the basic mediator of cooperative learning processes, we considered the possibility of explore the link between language and the mechanisms involved in cooperative learning. In summary, from this theoretical framework we hope to identify the forms adopted by virtual cooperative language in relation to their essential mechanisms.

\section{Method}

The present work constitutes an exploratory research based in a case study (Yin, 1989).

The case includes the didactic sequence based on online cooperative activities with university students chosen lasted three weeks. The teaching and learning process took place in a virtual university classroom.

The learning task entailed the analysis of three cases corresponding to three types of experiences observed by teaching teams using ICT in training processes. The participants were fifteen students divided into three cooperative learning groups, and a consultant teacher, taking a module on planning teachertraining processes with Information and Communication Tech- 
nologies (ICT), worth 3 ECTS (European Credit Transfer System) credits, and which forms part of the Master programme in Education and ICT (E-Learning) at the Open University of Catalonia (UOC). All the students had professional qualifications and the majority also had postgraduate education and experience as student in an online environment.

Each group was required to provide a critical evaluation of the planning process in the in-depth study of a reference case, so as to draw conclusions in relation to achievements, difficulties, risks and challenges brought about by the introduction of ICT. The activity was performed by means of group discussion for the cooperative construction of knowledge. The exchange of opinions and evaluations, in each corresponding case, was geared to answering the question: What changes, and how, in the teaching learning process with the introduction of ICT? The final product was a report including a critical evaluation, which each group sent to the teacher.

The teacher provided instructions for performing the task and a guide for the cooperative construction of knowledge in line with the objective set. The number of messages exchanged by the students totalled 104: Group A, $\mathrm{n}=36$, Group B, $\mathrm{n}=37$, and Group C, $\mathrm{n}=31$.

\section{Categorization Unit, Coding System, Inter-Judge Reliability}

An essential aspect was the selection of a unit of analysis which different coders would be able to recognise reliably. It entails identifying discourse categories which account for the main interpsychological mechanisms of virtual cooperative learning. Fixed units such as words or whole messages are recognised objectively, but they do not always encompass properly the construct being investigated. However, units of meaning do adequately delineate the construct, but can lead to a subjective identification of the unit (Rourke, Anderson, Garrison, \& Archer, 2001).

In keeping with the research objectives, as the basic unit of categorisation we chose the thematic unit introduced by Henri (1992), namely a "unit of meaning," which is similar in form to the conventional thematic unit described by Budd, Thorp and Donohue (1967, cited in Garrison \& Anderson, 2003) as “...a single thought unit or idea unit that conveys a single item of information extracted from a segment of content” (p. 193).

The system of categories we developed combines the notions of mutual exclusivity and exhaustiveness (Chi, 1997); the resulting categories were informed by the theory in the first place, but were defined situationally, according to the data we obtained. Therefore, deductive and inductive analyses were combined. We also took into account some previous studies finding about analyse online discourse and interaction (Han \& Hill, 2007; Hara, Bonk, \& Angeli, 2000; Marcelo \& Perera, 2007). With the inductive component, from the data we generated the categories, undergoing a process of adjustment, definition and redefinition, which in some cases gave place to some subdivisions and in some others to the creation of new categories and the elimination or fusion of some others, until a satisfactory system was achieved.

Thus, based on the theory and previous studies, we created a first system of categories, grouped into three dimensions, which correspond to the interpsychological mechanisms of virtual cooperative learning: Psychosocial Relations, Construction of Meaning and Positive Interdependence.
The three discussion sequences of the three groups making up the case study were categorised using the Atlas-ti software (version 6). New situations which could not be included in any of the initial categories gave rise to new categories. Each new category was defined and exemplified so that it could be properly integrated into the initial general system. Some categories overlapping others were merged and defined more clearly. Any categories of the initial general system not found in the data were eliminated. The research team, made up of three researchers, met on many occasions to apply the category system and perfect their definitions. Similarly, on occasions when a researcher had categorised independently and there was apparent confusion or similarity between the categories, we proceeded to improve their definitions, merge some and eliminate others. Each category was assigned a code, which proved highly useful for managing the data.

Once the coding of the sequences from the three groups was completed, we proceeded to select one of them at random, so that it could be evaluated by two external judges. These judges received training in the category system, both in relation to their definitions and the dimensions adopted. In this process, ideas were discussed on the least precise categories, some definitions were improved and others were complemented with more examples.

A segmentation of the messages into thematic units was agreed upon (Strijbos, Martens, Prins, \& Jochems, 2006), with 216 items identified for coding, and we established what would signal agreement: general concurrence on the identification of codes on the same items. Each of the judges categorised independently, taking into account that each item had to be coded into only one category.

The reliability of the category system was tested by calculating the Kappa coefficient which corrects the possibility of agreement due to chance. When this coefficient was applied by the two external evaluators, the first one obtained .95 and the second .91 .

\section{Results and Discussion}

The principal purpose of this analysis was of identifying the languages that reflect the presence of the interpsychological mechanisms that favour online cooperation. As a result of this exploratory study, 21 discourse categories were identified which are presented in Figure 1.

Next, some definitions of those categories which had a higher frequency in the three mentioned interpsychological mechanisms of cooperation will be explained with examples.

Greetings $(G)$ : Communication act performing merely a social function. It could appear at the beginning of the message or as a sign-off, whether formally or informally. Examples:

"Hello everyone”, "Hello”, "See you”, "Yours”, "Greetings”, "Hiya!”.

Individual Accountability (IA): Meeting their responsibilities or showing individual commitment to the execution of the joint task. Also included in this category are the postings related to obtaining personal commitment to the execution of the joint learning activities. Example:

“...tonight I'll attach the file to my posting..."

Reinforcement/Approval (RA): expresses agreement with previous postings or the content of the messages. Examples:

"...I think your work proposal is right”, "I agree with E01, with his views.” 


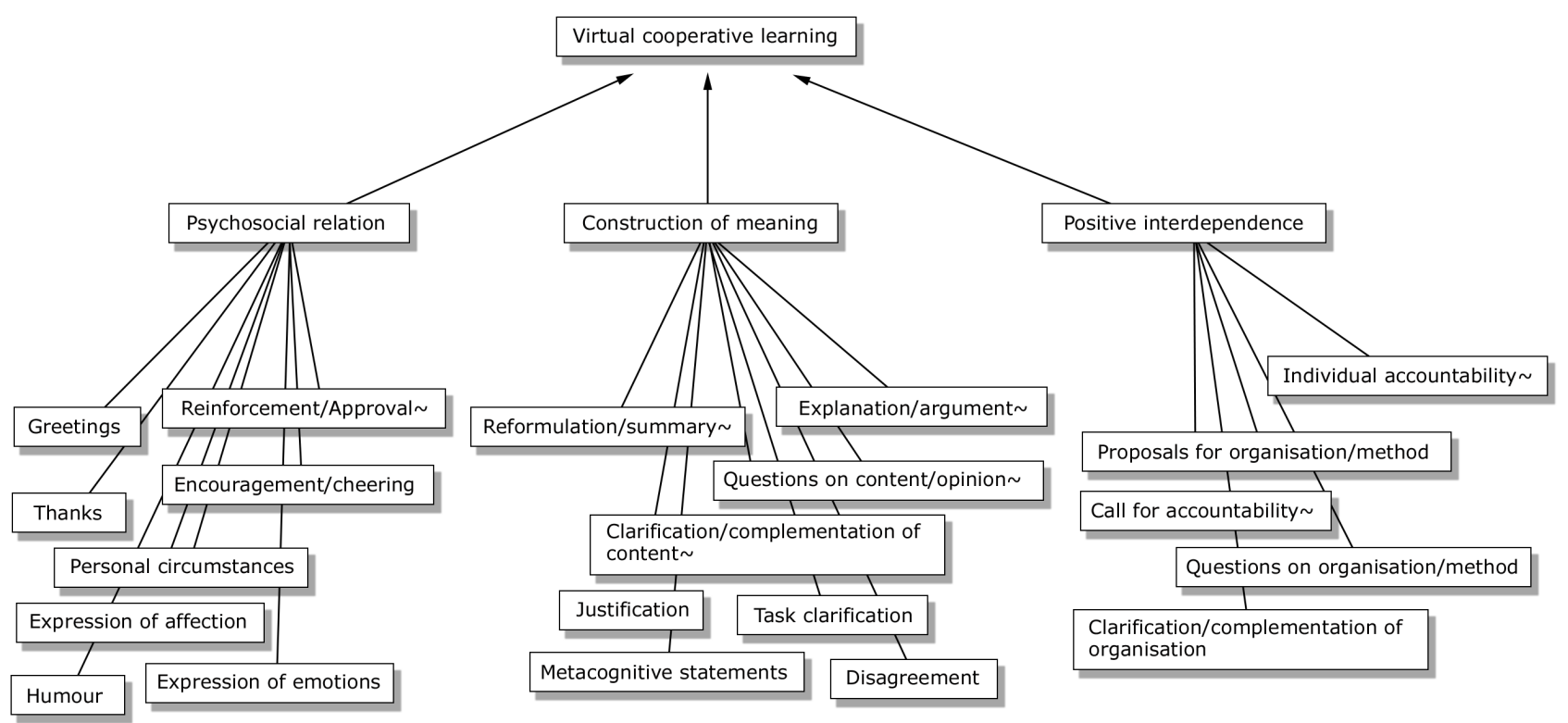

Figure 1.

Virtual cooperative discourse categories.

Explanation/argument (EArg): Statements aimed at enhancing others' understanding of an idea, content, concept or procedure, expressing their own viewpoint by means of opinions, perspectives or reflections supported with arguments. It is more elaborate than "Clarification/complementation" because it may contain descriptions, comparisons, definitions or enumerations of qualities or characteristics of the object or the contents of the explanation. Included in this category are the statements aimed at convincing others of an idea, content, proposal or procedure, by providing evidence. This argumentation is also done to substantiate or support ideas, clarifications, explanations or proposals made by other members of the group. Example:

"With regards to the effectiveness of training activities, I think that in the project of face-to-face classroom with ICT, there are two distinctive moments in the process: a training moment and a sensitisation moment:

Training: a training programme for teachers is established, both in the didactic methodology of constructive, participative and meaningful learning and with the use of ICT in the classroom. Awareness raising: by means of the process of sensitisation and evaluation of the prototype, it can be argued - by both students and teachers - that a change in methodology and the use of ICT bring about an improvement to learning."

The disagreement category was not identified in Group A and its frequency was very low in the other two groups (1 in Group B and 2 in Group C). In Group B the category expression of affection was not identified, but in Group A it appeared with a frequency of 11 times. In Group C all categories were identified but with the lowest total of frequency.

We will now present the results in relation to the interpsychological mechanisms in cooperative learning linked to the categories we identified in the analysis. Figure 2 shows a percentage comparison between the total frequency results of the categories of the three interpsychological mechanisms.

The greatest percentage corresponds to psychosocial rela-
Summary

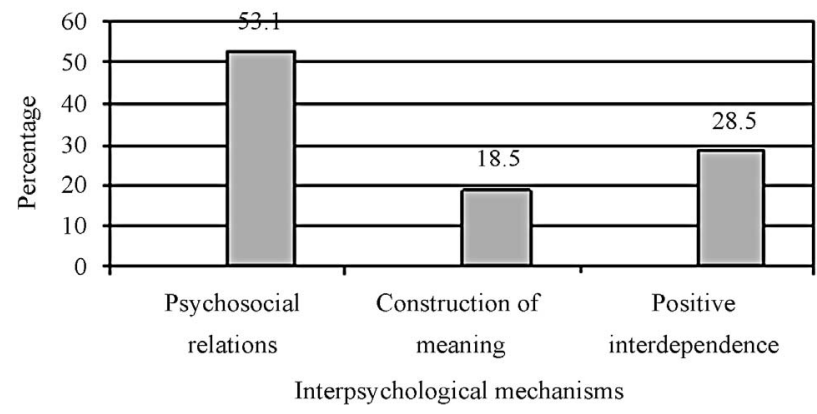

Figure 2.

Percentage summary of the discourse categories.

tions (53.1). It makes sense that this is the case because in online asynchronous communications it is common to find language related to establishing and maintaining these relations, such as: greetings, thanks, reinforcements, encouragement, expression of emotions; all of which contribute to the generation of social dialogue and serve to substitute certain characteristics typical of non-verbal communication, such as glances and gestures, which strengthen relations among members.

Similarly we can observe certain differences between the categories themselves inside each of these mechanisms; therefore, in subsequent figures we will show and comment on the categories' percentage per mechanism.

\section{Psychosocial Relations}

As commented on earlier, psychosocial relations include all those student postings which motivate and reinforce the group dynamics, social relations and the affective life of a Virtual Cooperative Learning group.

Figure 3 shows that, within psychosocial relations, the category with the highest percentage of frequency is greetings (40.9). 
This category also has the highest frequency (114) among all categories. This is due to the fact that in a virtual environment of asynchronous communication it is customary to include, in each message, greetings and goodbyes, both formal and informal, which contributes to establishing cordial relations among the group members.

Although lagging behind greetings by a considerable margin, reinforcement/approval has the second highest percentage (19.4) within psychosocial relations. It is also one of the categories with the highest frequency (54), in relation to the rest of the categories. In comparison to Garrison and Anderson's (2003) model in the social presence dimension-one of the dimensions considered as a starting point for the definition of the psychosocial relations categories-we find concurrence in the identification of categories expressing greetings, humour, expressions of affection, emotions, personal circumstances and agreement, although they are not defined in exactly the same way.

There are also marked differences in the distinction some of these researchers make between categories, indicators, subcategories and dimensions. For Garrison \& Anderson (2003), social presence corresponds to the whole dimension; the same for Marcelo and Perera (2007), who actually call it social dimension. However, for Han and Hill (2007), social presence is an indicator within the community category. In this same sense, Garrison and Anderson (2003) identify expression of emotions and resorting to humour as indicators of affection; whereas Marcelo and Perera (2007) identify expression of emotions as a subcategory within affection, but they do not include the humour category, which seems implicit in another category within the same dimension, called leisure.

In our case, in line with the way we defined these categories and the manner we presented the data analysed, we have chosen to consider affection, expression of emotions and humour as discourse categories which are differentiated from each other and serve to provide valuable nuances in the effort to maintain psychosocial relations.

Furthermore, among the eight categories associated with psychosocial relations, we identified two that were not present in the previously reviewed models: encouragement/cheering and thanks (encouragement/cheering, 33 and thanks, 27). The pre- sence and frequency of these two new categories lead us to posit that within the technique of Virtual Cooperative Learning we analysed, expressions of encouragement, cheering and thanks, are all essential characteristics to create and maintain motivation in the group towards cooperation. The following quote shows how a student encourages and/or cheers others within the group to continue working jointly.

“Come on!”, “Come on! We are doing well”, “...let’s hope we do well!"

"I sincerely thank you for your interest and motivation."

\section{Construction of Meaning}

The categories associated to this mechanism include those postings related to the generation of joint knowledge. Figure 4 shows the category with the highest percentage: explanation/ argument (35.1). In terms of percentage, it is followed by the categories reformulation/summary (19.6), questions on content/ opinion and clarification/complementation of content (14.4), which provides a snapshot of the predominant types of discourse used, which include explicative and argumentative texts. The low percentage attained by task clarification was to be expected.

Something similar can be stated about the category metacognitive statements. Strictly sticking to the definition of this category, it is not very common for students to state, throughout the debate, whether they have learned or improved their knowledge as a result of the interaction. These statements are more common at the end of the discussion and this is what happened in the three groups studied, which explains why this category's probability of incidence is low in comparison to others such as explanation/argument or reformulation/summary.

Justification and disagreement are also among the categories with the lowest percentage of frequency; the lack of disagreement may mean that students feel less need to justify their contributions throughout the debate. The higher percentage of $e x$ planation/argument may have a bearing on the low frequency of disagreement, given that more elaborate ideas may appear clearer and more convincing to the rest of the group.

The higher percentage of explanation/argument can be at-

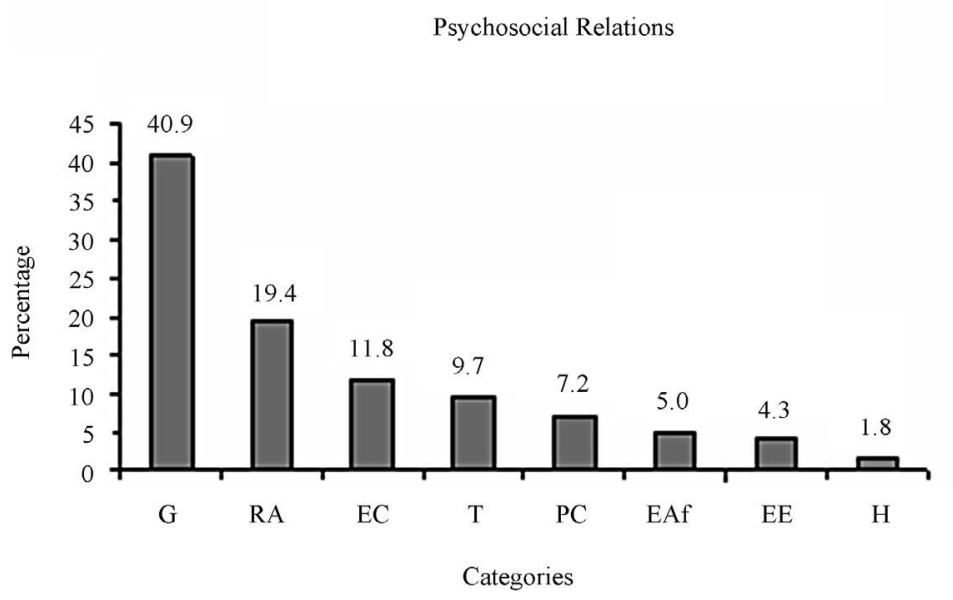

\begin{tabular}{|ll|}
\hline G & Greetings \\
RA & Reinforcement/Approval \\
EC & Encouragement/Cheering \\
$\mathrm{T}$ & Thanks \\
PC & Personal Circumstances \\
EAf & Expression of affection \\
EE & Expression of emotions \\
$\mathrm{H}$ & Humour \\
\hline
\end{tabular}

Figure 3.

Percentage of psychosocial relation categories. 


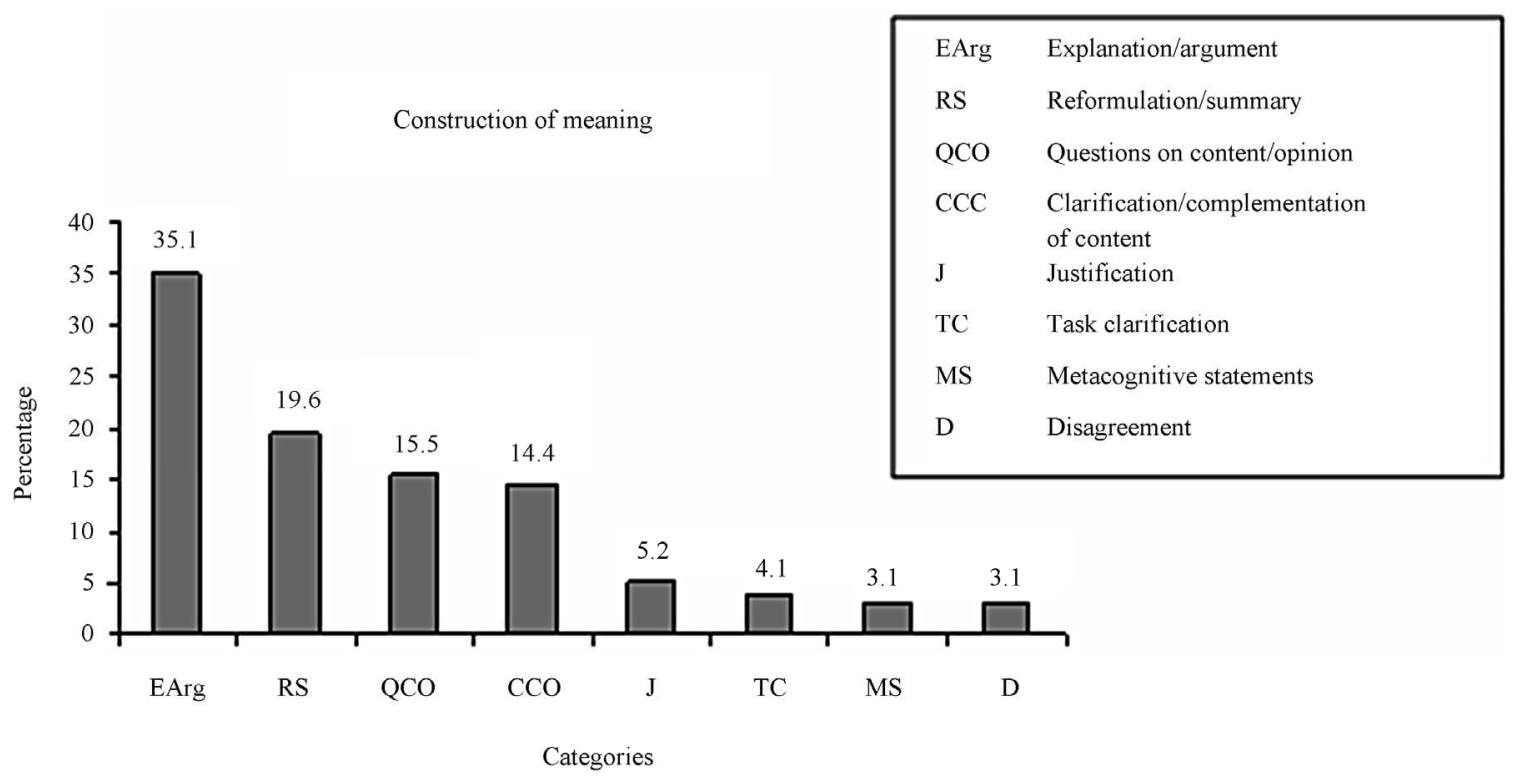

Figure 4.

Percentage of construction of meaning categories.

tributed to the fact that written asynchronous discourse affords more time for deliberation and the elucidation of ideas. It is less likely for students to post unfinished or poorly developed statements and/or those only directed to clarify or complement ideas.

\section{Positive Interdependence}

This interpsychological mechanism includes those postings that reflect the mutual dependency between the group members in order to achieve the group goals. In the groups analysed, an interdependence of goals was established, where each member's success was linked to the rest of the team's and vice versa.

A key issue in the generation of positive interdependence is for the group members to be held individually accountable in the attainment of the group goal (Johnson \& Johnson, 1999). In the students' discourse, this is clearly evidenced in the category individual accountability, which has the highest percentage (38.3) among the five categories linked to this mechanism. The frequency this category has in relation to the total is the second highest (57).

Figure 5 shows that next down in line, lagging behind by almost 20 points, are: proposal for organisation/method (20.8) and calls for accountability (19.5). An example of the latter is shown in the following quote, where a student (Student 15) appeals to another:

“...Please, S15, can you complete, correct or comment on anything you deem appropriate...”

The difference between the percentage shown by the category individual accountability (38.3) and the category call for accountability (19.5) indicates that the frequency with which students show their commitment to the task and goal was greater than the need to request commitment from others or make clear the need for contributions from other members.

The category with the lowest percentage is clarification/complementation of organisation. However, there are more proposals for organisation/method:
“...OK, mates, I suggest the following structure to organise our postings in the debate, so that we can complete the activity happily, if you agree, let's do it, if anybody else has another scheme let's discuss it soon. Relevance of the planning strategy followed, taking into account the educational needs and the characteristics of the context where the activity takes place, on 9th, 10th and 11th April...”

The three interpsychological mechanisms, identified by means of the categorisation of the discourse in the three groups, occur in an interlinked manner. It was apparent that psychosocial relations and positive interdependence are essential in enabling the joint construction of meaning, which is in turn both a mechanism and the main goal in a cooperative learning process.

\section{Conclusions and Future Lines of Research}

Our empirical data are from a course of three weeks, carried out by small groups of students, making it a very short time scale for examining the development of the discourse in peer cooperation. However, we gained two insights from the study:

First, in this case study, by means of discourse analysis we have identified types of discourse that can account for positive interdependence, construction of meaning and psychosocial relations, which are the mechanisms found at the basis of a cooperative learning process. The categories show the forms adopted by language in a virtual cooperative learning situation, in relation to their essential mechanisms.

Although previous research was taken into account, the discourse categories were defined from our own research data, which has allowed us to identify categories specific to virtual cooperative learning, such as those related to positive interdependence, which are not present in other research carried out in a virtual context.

Second, our case study in this paper demonstrates that the types of discourse prevailing in student interaction are those linked to psychosocial relations, followed by those linked to positive interdependence and to a lesser extent by those related 

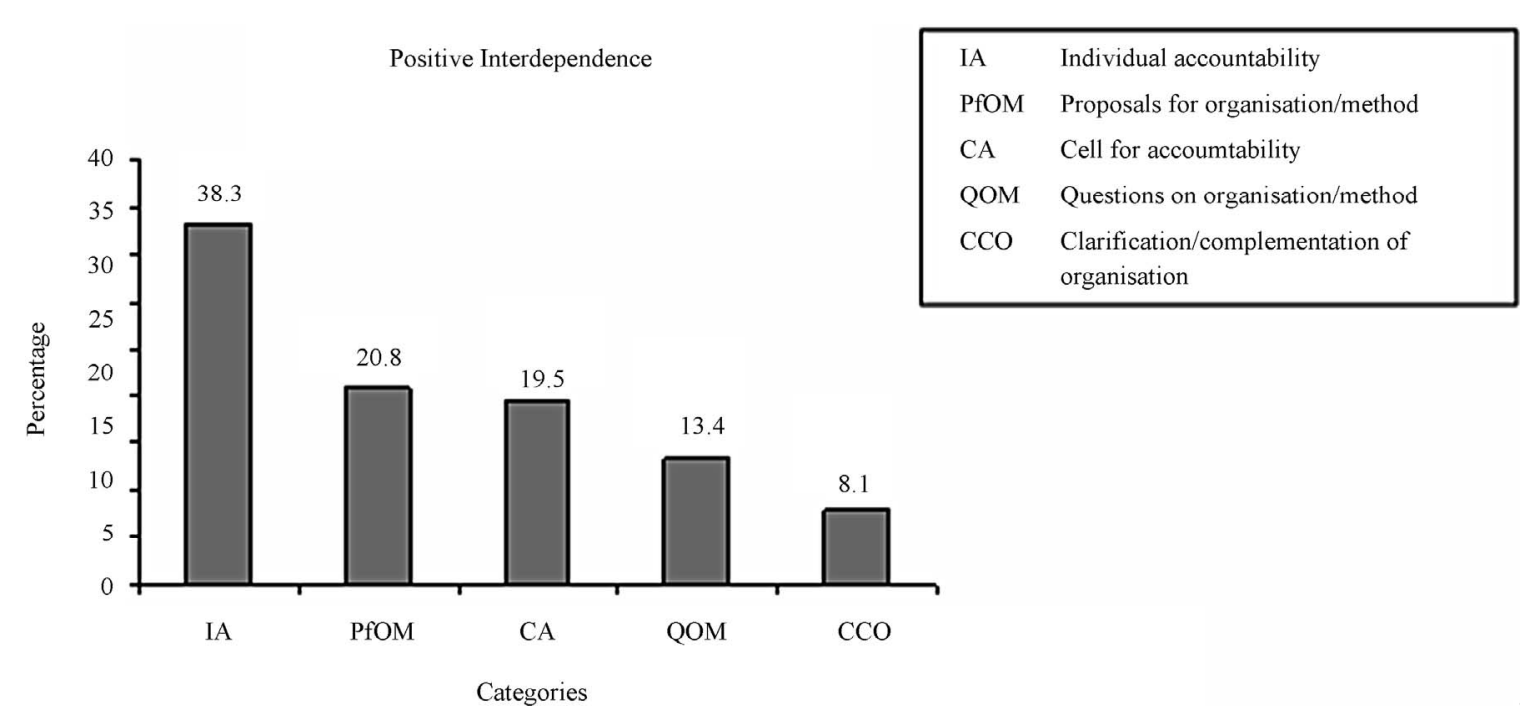

Figure 5.

Percentage of positive interdependence categories.

to the construction of meaning. In this process, some types of discourse are more powerful than others and represent the materialisation of some cognitive skills which are not always found in the same manner, or with the same frequency, in all groups or in all students. This leads us to ponder the need to encourage the types of discourse which facilitate joint construction in virtual cooperative learning.

In terms of the prevalence of psychosocial relations in the interaction and the low frequency of discourse related to the construction of meaning, our results concur with previous research carried out in virtual contexts, which analyse asynchronous discourse in forums of learning communities, and which have obtained the highest frequency in the social dimension and the lowest in the cognitive dimension (Marcelo \& Perera, 2007). The social dimension seems to be essential in the creation of a learning community reliant on cooperation and a sense of belonging, but beyond the interpretation of these differences it is worth adding that, in asynchronous text-based communication, students make up for the lack of certain aspects typical of faceto-face communication by using a discourse favourable to social dialogue and open communication, which would explain also their high frequency in discourse. Reinforcement or approval has already been identified in a previous study in face-toface education, but encouragement or cheering and thanks are characteristic of virtual cooperative learning.

These conclusions lead to a key reflection: the need to make the group participants aware of what is expected of them: the cognitive challenge implied by the task; the need to coordinate their efforts interdependently; the importance of language and communication in this process. Showing examples of the types of language by means of which their ideas are expressed and defended, by means of which meaning is shared and negotiated, seem to us as a key issue to enable progress in virtual cooperative learning and promote its self-regulation.

In this sense, by observing the process and the types of student discourse, the teacher's role may prove essential during the interaction, both in a preparatory phase and in establishing the initial conditions of the situation, as well as through their postings throughout the process.
In the case we analysed, the teacher established the initial conditions for the situation, providing instructions for the task and a guideline for the development of the discussion. Although she was available for consultation, her contributions were made mainly at the beginning and at the end of the group interaction, encouraging interaction in a general manner. Recognising the mechanisms typical of cooperative learning by means of language may enable students and teachers alike to gear their postings towards negotiation and implementation in a more effective manner, during the discussion process. This is especially true in situations such as the one experienced by one of our study groups, which took longer in establishing the initial conditions.

With regards to possible lines of research and advancement, it seems indispensable to contrast the language categories identified in this research with those of the discourse in other practices of virtual cooperative learning, both in terms of the implementation of the case study technique as well as in other types of tasks, so as to continue advancing in the identification and characterisation of the mechanisms underpinning its effectiveness in learning. It is also worth comparing the way the interpsychological mechanisms, typical of virtual cooperative learning, manifest themselves, the types of language characterising them and the way that the construction of meaning develops.

It would also be worthwhile to contrast these results with the analysis of other sequences in which the teaching objectives were clearly aimed at achieving exploratory forms of discussion, which would explicitly encourage language linked to the construction of knowledge and promote negotiation and implementation of the constructed meaning, in adequate equilibrium and respecting the students' strategies and styles, at the beginning, during and at the end of the process.

Our case study in this paper demonstrates that it is possible to analyse the main interpsychological mechanisms involved in peer cooperation can be carried out by small groups of students. In terms of application, it is important to consider that for students to be able to explain, argue, reformulate, summarise, justify and disagree in a constructive way, they need to show discursive skills and abilities they do not always have and are ne- 
cessary to develop so as to achieve a joint construction of greater quality and more favourable to learning. Teachers and students alike would be aware of the mechanisms accounting for their progress and the existence of phases in the development of a virtual cooperative learning task. Therefore, in our opinion, there is a valid case for designing training programmes or projects which would take into account the results of this research to train students and teachers in recognising, observing and triggering the mechanisms and processes which are fundamental in virtual cooperative learning and facilitate and optimise their application.

\section{REFERENCES}

Abram, P., Scarloss, B., Holthuis, N., Cohen, E., Lotan, R., \& Schultz, S. (2002). The use of evaluation criteria to improve academic discussion in cooperative groups. Asia Pacific Journal of Education, 22, 16-27. doi:10.1080/0218879020220103

Alvarez, I. M., \& López, D. (2010). Behaviour regulation during joint knowledge construction in cooperative tasks within virtual written and asynchronous learning environments. Cultura y Educación, 22, 419-438. doi:10.1174/113564010793351830

Brewer, S., \& Klein, J. D. (2006). Type of positive interdependence and affiliation motive in an asynchronous, collaborative learning environment. Educational Technology Research and Development, 54, 331-354. doi:10.1007/s11423-006-9603-3

Casanova, M. (2008). Cooperative learning in a virtual university context of asynchronous communication: A study on the process of peer interaction through discourse analysis. URL (last checked 16 December 2012). http://www.tdx.cat/TDX-0331109-134502/

Cazden, C. (1988). Classroom discourse: The language of teaching and learning. Portsmouth: Heineman.

Chi, M. (1997). Quantifying qualitative analyses of verbal data: A practical guide. Journal of the Learning Sciences, 6, 271-315. doi:10.1207/s15327809jls0603 1

Chou, C. (2003). Interactivity and interactive functions in web-based learning systems: A technical framework for designers. British Journal of Educational Technology, 34, 265-279. doi:10.1111/1467-8535.00326

De Wever, B., Schellens, T., Valcke, M., and Van Keer, H. (2006). Content analysis schemes to analyze transcripts of online asynchronous discussion groups; A review. Computers, and Education, 46, 6-28. doi:10.1016/j.compedu.2005.04.005

Dillenbourg, P. (2002). Over-scripting CSCL: The risks of blending collaborative learning with instructional design. In P. A. Kirschner (Ed.), Three worlds of CSCL. Can we support CSCL (pp. 61-91). Heerlen: Open Universiteit Nederland.

Dillenbourg, P., Schneider, D., \& Synteta, P. (2002). Virtual learning environments. In A. Dimitracopoulou (Ed.), Proceedings of the 3rd Hellenic Conference on Information, and Communication Technologies in Education (pp. 3-18). Rhodes: Kastaniotis.

Duran, D., \& Monereo, C. (2005). Styles and sequences of cooperative interaction in fixed and reciprocal peer tutoring. Learning and Instruction, 15, 179-199. doi:10.1016/j.learninstruc.2005.04.002

Edwards, D., \& Mercer, N. (1987). Common knowledge. The development of understanding in the classroom. London: Methuen.

Garrison, D., \& Anderson, T. (2003). E-learning in the 21st century. New York: RoutledgeFalmer.

Gunawardena, C., Lowe, C., \& Anderson, T. (1997). Analysis of a global online debate and the development of an interaction analysis model for examining social construction of knowledge in computer conferencing. Journal of Educational Computing Research, 17, 395431. doi:10.2190/7MQV-X9UJ-C7Q3-NRAG

Han, S., \& Hill, J. (2007). Collaborate to learn, learn to collaborate: Examining the roles of context, community and cognition in asynchronous discussion. Educational Computing Research, 36, 89-123. doi:10.2190/A138-6K63-7432-HL10

Hara, N., Bonk, C. J., \& Angeli, C. (2000). Content analysis of online discussion in an applied educational psychology course. Instructional Science, 28, 115-152. doi:10.1023/A:1003764722829

Henri, F. (1992). Computer conferencing and content analysis. In A. Kaye (Ed.), Collaborative learning through computer conferencing: The Najaden papers (pp. 117-136). Berlin: Springer-Verlag.

Hogan, K., Nastasi, B., \& Pressley, M. (2000). Discourse patterns and collaborative scientific reasoning in peer and teacher-guided discussions. Cognition and Instruction, 17, 379-432. doi:10.1207/S1532690XCI1704_2

Hung, D., \& Der-Thanq, Ch. (2001). Situated cognition, Vygotskian thought and learning from the communities of practice perspective: Implications for the design of web-based E-learning. Educational Media International, 38, 3-12.

Järvela, S., \& Hakkinen, P. (2002). Web-based cases in teaching and learning-The quality of discussions and a stage of perspective taking in asynchronous communication. Interactive Learning Environments, 10, 1-22. doi:10.1076/ilee.10.1.1.3613

Jermann, P., \& Dillenbourg, P. (2008). Group mirrors to support interaction regulation in collaborative problem solving. Computers \& Education, 51, 279-296. doi:10.1016/j.compedu.2007.05.012

Johnson, D., \& Johnson, R. (1999). Learning together and alone: Cooperative, competitive and individualistic learning. Needham Heights: Allyn \& Bacon.

Jonassen, D., \& Kwon, H. (2001). Communication patterns in computer mediated versus face-to-face group problem solving. Educational Technology Research and Development, 49, 35-51. doi:10.1007/BF02504505

Kanuka, H., \& Anderson, T. (1998). Online social interchange, discord, and knowledge construction. Journal of Distance Education, 13, 5774.

Laurillard, D. (2009). The pedagogical challenges to collaborative technologies. Computer-Supported Collaborative Learning, 4, 5-20. doi:10.1007/s11412-008-9056-2

Lipponen, L., Rahikainen, M., Hakkarainen, K., and Palonen, T. (2002). Effective participation and discourse through a computer network: Investigating elementary students' computer-supported interaction. Journal of Educational Computing Research, 27, 353-382.

Ludvigsen, S. R. (2011). What counts as knowledge: Learning to use categories in computer environments. Learning, Media and Technology, 37, 40-52. doi:10.1080/17439884.2011.573149

Marcelo, C., \& Perera, V. (2007). Communication and e-learning: Didactic interaction in new learning environments. Revista de Educación, 343, 381-429.

Mercer, N. (2000). Words and minds: How we use language to think together. Londres: Routledge. doi:10.4324/9780203464984

Mercer, N. (2004). Sociocultural discourse analisys: Analysing classroom talk as a social mode of thinking. Journal of Applied Linguistics, 1, 137-168. doi:10.1558/japl.2004.1.2.137

Naidu, S., \& Järvelä, S. (2006). Analyzing CMC content for what? Computers \& Education, 46, 96-103. doi:10.1016/j.compedu.2005.04.001

Onrubia, J., \& Engel, A. (2010). Strategies for collaborative writing and phases of knowledge construction in CSCL environments. Computers \& Education, 53, 1256-1265. doi:10.1016/j.compedu.2009.06.008

Panitz, T. (1996). Collaborative versus cooperative learning: A comparison of the two concepts which will help us understand the underlying nature of interactive learning. URL (last checked 16 December 2012).

http://home.capecod.net/ tpanitz/tedsarticles/coopdefinition.htm

Perit, M., Zemel, A., \& Stahl, G. (2009). The joint organization of interaction within a multimodal CSCL medium. Computer-Supported Collaborative Learning, 4, 115-149. doi:10.1007/s11412-009-9061-0

Rourke, L., Anderson, T., Garrison, D., \& Archer, W. (2001). Methodological issues in the content analysis of computer conference transcripts. International Journal of Artificial Intelligence in Education, 12, 8-22.

Rusbult, C., \& Van Lange, P. (2003). Interdependence, interaction and relationships. Annual Review of Psychology, 54, 351-375. doi:10.1146/annurev.psych.54.101601.145059 
Salmon, G. (2002). Mirror, mirror, on my screen. Exploring online reflections. The British Journal of Educational Technology, 33, 383396. doi:10.1111/1467-8535.00275

Schrire, S. (2006). Knowledge building in asynchronous discussion groups: Going beyond quantitative analysis. Computers \& Education, 46, 49-70. doi:10.1016/j.compedu.2005.04.006

Strijbos, J., Martens, R., Prins, F., \& Jochems, W. (2006). Content analysis: What are they talking about? Computers \& Education, 46, 2948. doi:10.1016/j.compedu.2005.04.002

Van Boxtel, C., Van der Linden, J., \& Kanselaar, G. (2000). Collaborative learning tasks and the elaboration of conceptual knowledge. Learning and Instruction, 10, 311-330.

doi:10.1016/S0959-4752(00)00002-5
Volet, S., Summers, M., \& Thurman, J. (2008). High-level co-regulation in collaborative learning: How does it merge and how is it sustained. Learning and Instruction, 19, 128-143. doi:10.1016/j.learninstruc.2008.03.001

Wegerif, R. (2006). A dialogic understanding of the relationship between CSCL and teaching thinking skills. International Journal of Computer-Supported Collaborative Learning, 1, 143-157. doi:10.1007/s11412-006-6840-8

Wertsch, J. (1985). Vygotski and the social formation of mind. Cambridge: Harvard University Press.

Yin, R. K. (1989). Case study research: Design and methods. London: Sage Publications. 